University of Nebraska - Lincoln

DigitalCommons@University of Nebraska - Lincoln

To Improve the Academy

Professional and Organizational Development Network in Higher Education

1995

Improving Teaching Across the Academy: Gleanings From

Research

Ben Ward

Follow this and additional works at: https://digitalcommons.unl.edu/podimproveacad

Part of the Higher Education Administration Commons

Ward, Ben, "Improving Teaching Across the Academy: Gleanings From Research" (1995). To Improve the Academy. 350.

https://digitalcommons.unl.edu/podimproveacad/350

This Article is brought to you for free and open access by the Professional and Organizational Development Network in Higher Education at DigitalCommons@University of Nebraska - Lincoln. It has been accepted for inclusion in To Improve the Academy by an authorized administrator of DigitalCommons@University of Nebraska - Lincoln. 


\section{Improving Teaching Across the Academy: Gleanings From Research}

\section{Ben Ward}

Western Carolina University

The field of faculty development is at least thirty years old, and although we have learned many things about improving teaching skills during that time, we have not developed many definitive answers to the larger questions of our craft; e.g., how do we raise the status and quality of teaching across an entire institution? This article surveys the research literature to ascertain what we do know about these questions, with the hope that it will stimulate a dialogue among faculty developers that will yield a fuller understanding of these broad issues.

More than merely a title for this publication, To Improve the Academy represents the raison d'être for the POD Network as well as for most of the centers and programs represented among POD members. It calls attention to the worthy but challenging goal to which many of us have dedicated our professional careers. We seek to improve the centerpiece of the academy, the one aspect of higher education that the general public, most governing boards, many legislators, nearly all students, and a majority of faculty members consider to be of paramount importance: the teaching-learning process.

If our goal is to improve teaching and learning across the academy, our challenge is much more complex than it would be for improving the teaching skills of an individual instructor. While most of us are probably well-qualified to diagnose the needs of an individual instruc- 
tor and guide him or her toward improved teaching, such a one-on-one approach is not likely to have a widespread impact on the overall quality of teaching simply because it is too labor intensive, time consuming and costly. Improving teaching and learning on a larger scale requires an understanding principles of organizational change as well as the dynamics of faculty and instructional development. Gaff and Simpson (1994), based on their review of faculty development practices in the U.S. over the past 30 years, emphasize the need for a broad approach which addresses all aspects of faculty endeavor. It is essential, therefore, that we know how to capture the attention and interest of large numbers of instructors, enlist them as in-house change agents, and cultivate a broad-scale movement for improving teaching and learning.

When I consider the magnitude of our challenge, I envision the ant in the old "High Hopes" song who was determined to "move the rubber tree plant." Like the ant, I am eternally optimistic. I believe that, collectively, we can move the quality of teaching and learning to a higher level, but, it will require extensive collaboration and cooperation. Unfortunately, the current state of our knowledge forces us to rely heavily on instinct, intuition, and experience. While we have learned much by trial and error over the past twenty years or so and those of us who have stumbled into pitfalls and banged our noses into various barriers can leave warning signs along the way for others who follow, we have not yet produced an authoritative "road map" to guide us toward our goal. As I exchange ideas with colleagues at the POD conference and enjoy their interchange on the e-mail network, I get the uneasy feeling that we are groping in the dark with only a match to light our way. We offer a variety of activities in hopes of boosting the quality of teaching, but we have not yet cleared a path, put up a string of lights, and prepared a Baedeker to guide us toward the goal of improving teaching and learning across the academy.

Considering the complexity of broad-scale efforts to improve teaching, we need a fuller picture of the forces that affect the process. For example, we need to know more about what motivates faculty to invest time in improving their teaching, how faculty cope with competing pressures for their time and attention, how administrative policies and procedures affect the campus climate for improving 
teaching, and the potential of established reward structures to encourage or discourage improvement of teaching. If we could explain how these elements interact and begin to identify some of the factors that tend to promote, support or otherwise "drive" the teaching improvement process and the forces that tend to oppose or restrain our efforts, we could be much more systematic in designing programs and services.

I propose, therefore, that we begin a long-term, collaborative project to answer the question, What does it take to raise the status and quality of teaching across an entire institution? Perhaps some of us might write POD research grants to address some aspect of this question. Maybe our annual conference could include opportunities to reflect on the ramifications of this issue, or better yet, present research findings for examination and discussion. Of course, this publication would be an ideal forum for airing our opinions and conclusions. Surely, if we focus the knowledge and experience of all POD members on such a fundamental question, we can generate more light on the path to improving teaching and learning across the academy.

My purpose in this article is to initiate a dialogue based on a few gleanings from research on college teaching. Admittedly, the research is sparse and not as conclusive as we might like, but there is enough evidence to inform our dialogue. My hope is that many others will critique, correct, or otherwise add to what I have to say so that we can sustain the dialogue and eventually arrive at a fuller understanding of the process of improving teaching and learning.

\section{Gleanings from Selected Research}

In a comprehensive review of the history of research on college teaching across the twentieth century, McKeachie (1990) identifies five areas that have been the focus of research: class size, teaching/learning methods, evaluation of teaching, teaching and technology, and cognitive psychology. Most of this research has focused on teaching methods and evaluation, particularly student ratings of instruction. These two areas have produced the most conclusive findings. Researchers tend to agree that different teaching methods may be effective for different purposes and that no single method is 
superior for all situations (Costin, 1972; Dubin \& Taveggia, 1968; McKeachie, 1970). Teaching effectiveness is situation specific, depending on the subject matter, the students, and the setting (McKeachie, Pintrich, Lin, \& Smith, 1986). Substantial evidence also suggests that student ratings of instruction are reasonably valid and reliable (Cohen, 1980; Marsh, 1984). Beyond these points, there are numerous studies with little or no replication, and therefore, little consensus.

Fortunately, a few studies are helpful in identifying some of the factors involved in the process of improving teaching. These factors can be classified into the following three categories: (1) driving forces-factors which tend to support improvement of teaching; (2) neutral forces - factors which might be expected to have considerable influence on teaching improvement efforts, but which, according to research findings, actually have negligible impact; and (3) restraining forces-factors which tend to oppose improvement of teaching. This review shows that primary driving forces include faculty intrinsic motivation, consultation services related to improvement of teaching, and a positive institutional climate for teaching. Neutral forces include faculty career age, end-of-course student ratings that are not supplemented with consultation or other assistance, and, surprisingly, the institutional reward system. Major restraining forces include low perceived need to improve teaching among faculty (i.e., high sense of self-competence in teaching), and a negative institutional climate for teaching.

While these factors probably do not represent all of the forces involved in the complex process of improving teaching, they provide a useful starting point for understanding the process of improving teaching on a broad scale. Points pertaining to student ratings and teaching consultation services are based on substantial evidence and are probably the most conclusive. Although other points are not supported by voluminous evidence, the studies cited are generally of high quality. Additional research will be necessary before a definitive analysis of the teaching improvement process is possible. In the meantime, this analysis is offered as a basic foundation for better understanding of that process. 


\section{Driving Forces}

\section{Faculty Intrinsic Motivation}

The significance of faculty intrinsic motivation for improving teaching was implied in findings from one of the first large-scale studies of faculty development practices. Based on data from a national survey, Centra (1976) found that the most active participants in faculty development programs were "good teachers who wanted to get better" (p. 25). In view of the fact that "participation in most development activities is usually voluntary" (p. 27), the presence of intrinsic motivation seems probable. When good teachers voluntarily seek out and participate in teaching improvement programs without any promise of extrinsic rewards, intrinsic motivation is apparently high. According to Farmer (1993), "The power of intrinsic rewards to motivate senior faculty has been traditionally undervalued" (p. 52).

Additional indicators of faculty intrinsic motivation were found in the Project for Faculty Development Program Evaluation (Blackburn, Boberg, O'Connell, \& Pellino, 1980). In their final report on this project, these researchers observe that "faculty apparently have a highly internal set of criteria for judging their classroom performance, one which is supported by their personal experience with students but is relatively free from colleagues' and supervisors' opinions"'(p. 21). Coupled with the finding that "faculty value very highly their teaching role" (p. 15), this report reinforces Centra's suggestion of the significance of intrinsic motivation. If faculty rely primarily on their own individually developed criteria for judging their teaching performance and hold themselves to high standards, then these "highly internal" judgments may be a source of intrinsic motivation for participating in teaching improvement activities.

The most direct and persuasive evidence of faculty intrinsic motivation for improving teaching is found in a study of institutional policies, particularly extrinsic reward structures, that influence faculty participation in faculty development programs and changes in teaching behaviors (O'Connell, 1983). O'Connell found that the degree of faculty participation in faculty development activities was not significantly affected by different institutional reward structures for promo- 
tion, tenure, and salary increases. To verify this finding, O'Connell surveyed faculty in selected institutions to more accurately measure their participation in faculty development activities and the degree of change in their teaching behavior. Results of this second phase of the study were "nearly identical" to those discovered in phase one, showing no significant differences between "faculty in colleges in which changed teaching highly influences rewards of promotion, tenure, and salary increases and faculty in colleges in which it does not" (p. 668). Based on these findings, O'Connell concludes that "faculty are innermotivated persons whose professional values move them to seek the rewards intrinsic to teaching regardless of the institutional policies that support that effort" (p. 662).

Although this study was limited to a relatively homogeneous group of liberal arts colleges, the conclusion is consistent with implications in the more heterogeneous studies conducted by Centra and Blackburn, cited above. Taken together, these three studies provide substantial support for the argument that faculty intrinsic motivation is a major driving force in the teaching improvement process.

\section{Teaching Consultation Services}

Since 1976, when Melnik and Sheehan described "The Clinic to Improve University Teaching," many institutions have offered teaching consultation services as part of their faculty development programs. As outlined in A Handbook for Faculty Development (Bergquist and Phillips, 1977), such services usually involve a threestage process in which an on-campus consultant guides faculty through a systematic analysis of teaching responsibilities related to one specific course. While research on the teaching consultation process is not abundant, two empirical studies (Erickson \& Erickson, 1979, and Wilson, 1986) and one critical review of literature on improving college teaching (Levinson-Rose \& Menges, 1981) support the opinion of Bergquist and Phillips (1977) that this type of consultation is "perhaps the most powerful methodology yet conceived for the actual improvement of in-class teaching" (p. 78). Findings from these three studies indicate that consultation services of this nature are driving forces for improvement of teaching. 
Erickson and Erickson (1979) evaluated the effectiveness of the teaching consultation process by comparing results of an experimental group and a control group of volunteer faculty at one institution. Results of the-study showed that "students of experimental group instructors perceived more positive change on teaching performance over the semester than did students of control group instructors," that "experimental group instructor self-ratings of improvement were more positive than those of control group faculty," and that "the responses of the experimental group instructors to the two questionnaires about the consultant and the consultation procedure were very positive" (p. 676). After conducting a follow-up study, these researchers concluded that "volunteer faculty who use the teaching consultation process consider it useful and well worth their time and effort, and that it results in significant, positive, and lasting changes in their classroom teaching skill performance" (p. 683).

A more recent study of teaching consultation services (Wilson, 1986) found similar results at a different institution. Wilson collected student ratings and faculty self-descriptions of teaching at the end of three offerings of the same course and provided two periods of extensive consultation between points of data collection. Differences in ratings were statistically analyzed and then juxtaposed with similar data from a comparison group of faculty who had received results of their student ratings without the benefit of consultation. Results indicated that (1) "The consultation process was associated with statistically important change in overall teaching effectiveness ratings for 52 percent of the faculty clients," and (2) the comparison group "showed no significant change in the ratings of their teaching" (pp. 209-210). This study adds support, therefore, to the case for teaching consultation services as a driving force for improving teaching.

In an article entitled "Improving College Teaching: A Critical Review of Research" (Levinson-Rose \& Menges, 1981), one study (Bray \& Howard, 1980) concludes that "videotape feedback with consultation" is the most effective method for improving teaching assistant instruction. Citing seven other studies of consultation in combination with student ratings, Levinson-Rose and Menges find that, although the quality of the studies varies widely, they "generally support the ratings/consultation intervention" (p. 412). Only two 
studies fail to support a ratings/consultation treatment, and one of these (Erickson \& Sheehan, 1976) was later redesigned and superseded by the highly supportive study by Erickson and Erickson, discussed above. The weight of existing research data, therefore, indicates that teaching consultation services are indeed one of the driving forces for improvement of teaching.

\section{A Positive Institutional Climate for Teaching}

As defined by Peterson et al (1986), organizational climate stems from "shared perceptions of patterns of organizational behavior" ( $p$. 81). These researchers present a conceptual model of "The Organizational Climate for Teaching and Learning" which hypothesizes a direct relationship between organizational climate and teaching/learning outcomes. Based on an extensive review of research literature, this model hypothesizes that the prevailing psychological climate at an institution has a direct affect on teaching and learning outcomes.

Support for this hypothesis is found in a recent study by LaCellePeterson and Finkelstein (1993). Based on responses from 111 faculty members on eleven New Jersey campuses, they conclude that "teaching vitality is, at least in part, a product of a positive teaching climate" (p. 21). Their findings suggest that elements of such a climate may include a stimulus-rich environment characterized by a wide array of opportunities for teaching enrichment, opportunities for collective/collaborative teaching, systematic brokering of opportunities for faculty development, and institution-wide faculty development programs.

A positive institutional climate for teaching may be the single most influential factor in efforts to improve teaching across an entire campus. When a majority of faculty perceive that teaching is important at their institution, their shared perception may create a general climate where improvement of teaching is accepted as the norm rather than as an admission of inadequacy. Once such a positive climate for teaching is established, faculty are more likely to be receptive to activities designed to improve teaching. Without such a climate, however, the impact of other driving forces, including faculty intrinsic motivation and teaching consultation services, may be severely weakened if not virtually squelched. 


\section{Neutral Forces}

\section{Faculty Career Age}

If faculty career age is at all a force to be considered in the teaching improvement process, it is extremely modest. In a critical review of research literature on aging and faculty performance, Blackburn and Lawrence (1986) conclude that correlations of teaching performance and age "are predicted to be as they are most often found, vacillating around 0.0 " (p. 273). Their review cites five studies which found "low order positive correlations" between teaching effectiveness and academic rank, but they point out that, since the rank of full professor may cover an age span of approximately 30 years, "even the weakest positive relationship is questionable" (p. 272). They also cite a few studies that show that "there is no strong relationship of student-judged teaching effectiveness and age" (p. 273).

Other evidence suggests that interest in teaching may increase with age (Rice \& Finkelstein, 1993, Fulton \& Trow, 1974) or, as modified by Baldwin and Blackburn (1983), at least increase again late in the career. There is no evidence, however, that senior faculty tend to become dominant figures in the teaching improvement process. Thus, faculty career age is not likely to be either a major driving force or a restraining force in efforts to improve teaching.

\section{End-of-Course Student Ratings}

A common practice at many colleges and universities is to collect student ratings of teachers and courses near the end of each term, tabulate the results, and return them to instructors with no additional feedback or consultation. Research shows that, under these conditions, student ratings have a negligible impact on improving teaching.

Rotem and Glasman (1979) reviewed nearly twenty years of literature on student ratings and concluded that, with the exception of two studies with methodological shortcomings, "none of the studies conducted in higher education demonstrated significant effects due to feedback on any of the dependent variables investigated" (p. 498). The main implication arising from their review was that "feedback from student ratings does not seem to be effective for the purpose of 
improving performance of university teachers" (p. 507). Cohen's meta-analysis of literature on this same topic (1980), while not supporting Rotem and Glasman's conclusion in all respects, reached the same general conclusion concerning the use of student ratings with no additional information or guidance: "instructors need more than just student-rating feedback to markedly improve their instruction. . . It is evident that when instructors are left to their own resources, ratings provide little help" (p. 338).

Although Marsh (1984) argues that "The introduction of a broad institution-based, carefully planned program of student evaluations of teaching effectiveness is likely to lead to the improvement of teaching" (p. 746), he makes it clear that a "carefully planned program" must be more than the unsupplemented feedback that is typical at many institutions. He finds that the results of Cohen's meta-analysis support his own findings and 'demonstrate that feedback from students' evaluations, particularly when augmented by consultation, can lead to improvement in teaching effectiveness" (p. 746, emphasis added). Without any such augmentation, however, the bulk of evidence shows that student ratings of teaching are a neutral force in the teaching improvement process.

\section{Institutional Reward System}

One of the most surprising findings in the research literature is that different types of institutional reward structures have little direct effect on faculty participation in faculty development activities. Based on an extensive review of the literature, Finkelstein (1984) concluded that faculty behavior is not related to institutional incentives. O'Connell (1983) investigated the question, "Does the degree of faculty participation in faculty development activities differ significantly between colleges in which changed teaching highly influences rewards of promotion, tenure, and salary increases and those in which it does not?" Analysis of data from 80 responding liberal arts colleges answered the question with a resounding "No."

Considering that O'Connell's study is the only one identified to date on this question and that it is limited to small liberal arts colleges, this finding must be held as tentative until additional research on the question accumulates. As O'Connell acknowledges, “A complex set 
of factors may be at work to reinforce sound teaching at the colleges in the study. Possibly no one factor can be isolated as the sole contributing influence" (p. 673). Indeed, it may be that a set of driving forces such as those discussed above and perhaps others not yet identified are powerful enough to override or negate the effects of the different reward structures. Although Fairweather's study of the relationship between teaching and compensation (1992) shows that faculty who spend the most time on teaching tend to be among the lowest paid, he does not address the question of whether a stronger link between teaching and compensation would motivate instructors to improve their teaching. Likewise, Berman and Skeff (1988) and Jabker and Halinski (1978) report that faculty members tend to view teaching as a very important activity, which is influenced by extrinsic rewards, but they do not explore the power of extrinsic rewards to improve teaching. It is possible that the impact of reward structures varies greatly for different types of institutions. At certain types of institutions, particularly small liberal arts colleges, the power of that force may be negligible, while at other types of institutions it may be much stronger. Until more conclusive evidence is accumulated, therefore, it seems appropriate to consider institutional rewards for teaching to be a neutral force for improving teaching.

\section{Restraining Forces}

\section{Low Perceived Need to Improve Teaching Among Faculty}

According to Blackburn, Pellino, Boberg, and O'Connell (1980), "Faculty don't believe they have any problem with their teaching" ( $p$. 35). Data from their study of nearly 2000 faculty at twenty-four institutions show that approximately 90 percent of the faculty judge themselves above average or superior teachers. This suggests that faculty have a high sense of self-competence for teaching and, consequently, must not feel a great need to improve.

This does not mean, however, that faculty are indifferent to or disinterested in improving teaching. Data from the same study show that most faculty place exceptionally high value on their teaching role. Therefore, the low perceived need to improve is probably modified by the high personal value of teaching. As a result many faculty are likely 
to be sympathetic to instructional improvement programs for their colleagues but feel little need to get involved in such activities for their own sake. This interpretation is supported by the finding that faculty think their colleagues need more help with teaching than they do. As stated by Blackburn et al., any individual faculty member is likely to say "I don't need help, but my peers do" (p. 35).

This attitude represents a restraining force on the teaching improvement process. In view of the multiple demands for faculty time and attention, it is difficult for many faculty members to schedule time for teaching improvement activities when their perceived need to improve is low. According to Nordvall (1982), "it is very difficult to institute change in an institution where there is little perceived need for change" (p. 42).

\section{Negative Institutional Climate for Teaching}

Any type of organizational climate which does not place high priority on effective teaching is likely to be a restraining force on efforts to improve teaching. If teaching is taken for granted or if improvement of teaching is assumed to be each instructor's individual responsibility with little or no visible organizational support, the impact of instructional improvement programs will probably be minimal. If most faculty members at a given institution become convinced that their administrators and colleagues place high value on research, publication, and grant writing and relatively less value on teaching, then motivation to put extra time and effort into improving teaching is likely to be undermined.

These points are consistent with the findings of Peterson et al. (1986), which indicate that the prevailing organizational climate is a dominant influence on teaching and learning outcomes. Since the Peterson model does not specify any particular type of climate, it can be applied to both positive and negative climates in regard to teaching. In the same way that a positive academic climate is a driving force for improving teaching, a climate where teaching is not highly valued is likely to be an obstacle in the teaching improvement process. As pointed out by Nordvall in The Process of Change in Higher Education Institutions (1982), some scholars argue that "piecemeal change is not effective; total institutional renewal is required to make change 
really count" (p. 33). If the prevailing organizational climate at a given institution is not favorable for improving teaching, then the change process may need to begin with reexamination of the institutional mission, reevaluation of administrative policies and procedures, and assessment of faculty motivation and educational values.

\section{Conclusion}

While this review is not comprehensive or conclusive, it does begin to sketch some of the parameters of the teaching improvement process. It suggests that any promising approach to improving teaching across an entire campus should begin with a thorough assessment of driving and restraining forces peculiar to the specific institution. After identifying the opposing forces that affect efforts to improve teaching, the strength of each force needs to be estimated. On campuses where restraining forces are dominant, the overall quality on teaching among the majority of instructors is not likely to change significantly in response to instructional improvement programs. Where driving forces slightly outweigh restraining forces, broad scale improvements may be possible if systematic intervention strategies are sustained over time, but the improvements are likely to be gradual and incremental in nature. Only when driving forces significantly outweigh restraining forces can extensive improvements be expected over a relatively short period of time. In general, college and university teachers on a given campus will be motivated to improve teaching to the degree that driving forces outweigh restraining forces.

Contrary to common opinion, the prevailing climate at a particular institution may be more heavily influenced by faculty values and beliefs than by administrators' policies and management practices. Since one of the main driving forces-faculty intrinsic motivation for teaching - and one of the main restraining forces - a high sense of self-competency in teaching - are both deeply rooted in faculty values and beliefs, these forces are likely to remain strong regardless of whether administrative policies and practices are supportive or unsupportive. According to Blackburn et al. (1980), faculty tend to be highly independent in judging their teaching, and their strong internal criteria are not heavily influenced by colleagues' and supervisors' opinions. 
It seems unlikely, therefore, that the collective commitment to teaching among faculty would be determined by anything other than their own internal standards. While the prevailing institutional climate for teaching probably stems from a complex interaction of various forces, faculty values and beliefs appear to be at the core.

Of course, the impact of institutional rewards for teaching deserves more detailed scrutiny. We may find that the institutional reward system can be a driving force for improving teaching at some institutions, a restraining force at others, and yet a neutral force elsewhere. No matter how this point turns out, it seems clear that institutional rewards for teaching-or lack thereof-is only one of many considerations in the process of improving teaching.

Apparently improvement of teaching requires a broad program of organizational development as well as intensive faculty development. Efforts must be aimed simultaneously at changing the academic climate for teaching and at changing faculty priorities and perceptions concerning the need to improve teaching. Teaching centers and organized faculty development programs do not bear sole responsibility for promoting such changes, but they surely should be in the forefront of the endeavor. If we are to achieve any measure of success in our efforts "To Improve the Academy," we need to take stock of the evidence and insights that are currently available and seek to fill in the gaps as quickly as possible.

\section{References}

Baldwin, R. G. \& Blackburn, R. T. (Eds.) (1983). College faculty: Versatile human resources in a period of constraint. New Directions for Institutional Research, 40. San Francisco: Jossey-Bass.

Bergquist, W. H. \& Phillips, S. R. (1977). A handbook for faculty development (Vol. 2). Washington D.C.: Council for Advancement of Small Colleges.

Blackburn, R. T., Pellino, G. R., Boberg, A., \& O'Connell, C. (1980). Are instructional improvement programs off-target? Current Issues in Higher Education, 1, 32-48.

Blackburn, R. T. \& Lawrence, J. H. (1986). Aging and the quality of faculty job performance. Review of Educational Research, 23, 265-290.

Bray, J. H. \& Howard, G. S. (1980). Methodological considerations in the evaluation of a teacher training program. Journal of Educational Psychology, 72, 62-70.

Centra, J. A. (1976). Faculty development practices in $U$ S. colleges and universities. Project Report 76-30. Princeton: Educational Testing Service. 
Cohen, P. A. (1980). Effectiveness of student-rating feedback for improving college instruction: A meta-analysis of findings. Research in Higher Education, 13, 321-341.

Costin, F. (1972). Lecturing versus other methods of teaching. British Journal of Teaching. 3, 4-30.

Dubin, R. \& Taveggia, T. C. (1968). The teaching-learning paradox: A comparative analysis of college teaching methods. Eugene, OR: Center for the Advanced Study of Educational Administration, University of Oregon.

Erickson, G. R. \& Erickson, B. L. (1979). Improving college teaching: An evaluation of a teaching consultation procedure. Journal of Higher Education, 50, 670-683.

Erickson, G. R. \& Sheehan, D. S. (1976). An evaluation of a teaching improvement process for university faculty. Paper presented at the annual meeting of the American Educational Research Association, San Francisco.

Fairweather, J. S. (1992). Teaching and the faculty reward System: Relationships between faculty activities and compensation. University Park: National Center for Postsecondary Teaching, Learning, and Assessment.

Farmer, D. W. (1993). Designing a reward system to promote the career development of senior faculty. New Directions for Teaching and Learning, 55. 43-53. San Francisco: Jossey-Bass.

Finkelstein, M. J. (1984). The American academic profession: A synthesis of social scientific inquiry since WWII. Columbus: Ohio State University Press.

Fulton, O. \& Trow, M. (1974). Research Activity in American Higher Education. Sociology of Education, 47, 29-73.

Gaff, J. G. \& Simpson, R. D. (1994). Faculty development in the United States. Innovative Higher Education, 18, (3), 167-76.

LaCelle-Peterson, M. W. \& Finkelstein, M. J. (1993). Institutions matter: Campus teaching environments' impact on senior faculty. New Directions for Teaching and Learning, 55, 21-32. San Francisco: Jossey-Bass.

Levinson-Rose, J. \& Menges, R. J. (1981). Improving college teaching: A critical review of research. Review of Educational Research, 51, 403-434.

Marsh, H. W. (1984). Students' evaluations of university teaching: Dimensionality, reliability, validity, potential biases, and utility. Journal of Educational Psychology, 76, 707-754.

McKeachie, W. J. (1990). Research on college teaching: A review. Washington, D.C.: ERIC Clearinghouse in Higher Education, 1970. ERIC document reproduction service no. ED 043789.

McKeachie, W. J. (1990). Research on college teaching: The historical background. Journal of Educational Psychology, 82 (2), 189-200.

McKeachie, W.J., Pintrich, P.R., Lin, Y.G., \& Smith, D.A.F. (1986). Teaching and learning in the college classroom: A review of the research literature. Ann Arbor: National Center for Research to Improve Postsecondary Teaching and Learning, The University of Michigan. 
Melnik, M. A. \& Sheehan, D. S. (1976). Clinical supervision elements: The clinic to improve university teaching. Journal of Research and Development in Education, 9, 67-76.

Nordvall, R. C. (1982). The process of change in higher education institutions. ERIC/AAHE Reports, \#7.

O'Connell, C. (1983). College policies off-target in fostering faculty development. Journal of Higher Education, 54, 662-675.

Peterson, M. W., Cameron, K. S., Mets, L. A., Jones, P., \& Ettington, D. (1986). The organizational context for teaching and learning. NCRIPTAL Publication, Ann Arbor, MI: National Center for Research to Improve Postsecondary Teaching and Learning.

Rice, R. E. \& Finkelstein, M. J. (1993). The senior faculty: A portrait and literature review. In New Directions for Teaching and Learning, 55. San Francisco: Jossey-Bass.

Rotem, A. \& Glasman, N. S. (1979). On the effectiveness of students' evaluative feedback to university instructors. Review of Educational Research, 49, 497-511.

Seldin, P. \& Associates (1990). How administrators can improve teaching. San Francisco: Jossey-Bass.

Weimer, M. (1990). Improving college teaching. San Francisco: Jossey-Bass.

Wilson, R. C. (1986). Improving faculty teaching: Effective use of student evaluations and consultants. Journal of Higher Education, 57, 196-211. 